Check for updates

Cite this: RSC Adv., 2017, 7, 19557

\title{
New insights into high temperature hydrothermal synthesis in the preparation of visible-light active, ordered mesoporous $\mathrm{SiO}_{2}-\mathrm{TiO}_{2}$ composited photocatalysts $\dagger$
}

\begin{abstract}
Qin Wu, Chen Liu, Jinjun Peng and Fujian Liu (D)*
Visible-light active, carbon doped and ordered mesoporous $\mathrm{SiO}_{2}-\mathrm{TiO}_{2}$ nanocomposites (C-OMS@TiO $2-x \mathrm{~s}$ ) were synthesized from the self-assembly of Si and Ti precursors with block copolymer templates (F127 and $\mathrm{P} 123)$, hydrothermally treated at $180^{\circ} \mathrm{C}$, and calcination or extraction for removing the templates. XRD patterns and TEM images indicate highly ordered mesopores were formed in $\mathrm{C}-\mathrm{OMS} \mathrm{OTiO}_{2}-\mathrm{XS}$, and $\mathrm{TiO}_{2}$ species with a high crystalline degree were homogeneously dispersed into the samples, which formed a stable "brick-and-mortar" nanostructure. $\mathrm{N}_{2}$ adsorption-desorption isotherms indicate very large BET surface areas $\left(224-553 \mathrm{~m}^{2} \mathrm{~g}^{-1}\right)$ and pore volumes $\left(0.45-1.4 \mathrm{~cm}^{3} \mathrm{~g}^{-1}\right)$ in these samples. EDX spectra and elemental maps further confirm successful doping and homogeneous dispersion of $\mathrm{TiO}_{2}$ nanocrystals in C-OMS@TiO 2 -xs. XPS spectra confirmed the doping of carbon atoms into the lattice of $\mathrm{TiO}_{2}$ species under high temperature hydrothermal conditions, which results in $\mathrm{C}-\mathrm{OMS} \mathrm{CTiO}_{2}-x \mathrm{~s}$ with enhanced visible light response properties, as confirmed by UV-vis diffuse reflectance spectra and photocurrenttime $(I-t)$ curves. Catalytic tests indicate that the synthesized $\mathrm{C}-\mathrm{OMS}\left(\mathrm{TTiO}_{2}-x \mathrm{~S}\right.$ show excellent activities for degradation of organic pollutants irradiated with visible light. For instance, degradation of highly concentrated rhodamine B (RhB, 100 ppm) can be completely catalyzed in the water within 50 min. This work provides a facile approach to the targeted synthesis of visible active and ordered mesoporous materials.
\end{abstract}

Received 2nd February 2017

Accepted 24th March 2017

DOI: $10.1039 / c 7 r a 01368 j$

rsc.li/rsc-advances

\section{Introduction}

$\mathrm{TiO}_{2}$ and its derived materials have received considerable attention because of their wide applications in the areas of water purification, solar cells, hydrogen production, photoelectric conversion and photocatalysis, ${ }^{1-16}$ which show characteristics such as good chemical stability, nontoxicity and low cost. ${ }^{1-19}$ It is well known that the structural characteristics such as crystallinity, morphology, and surface areas strongly affect their functionality. ${ }^{2,20,21}$ In general, $\mathrm{TiO}_{2}$ based materials with large BET surface areas and good crystallinity are always desired, which could largely enhance the degree of exposure and accessibility of anchored Ti sites to various guest molecules. ${ }^{2,20,21}$ These structural characteristics could largely enhance their performances in various research fields.

One of the most important applications of $\mathrm{TiO}_{2}$ based materials is photocatalysis. However, $\mathrm{TiO}_{2}$ is only sensitive to UV-light due to its large band gap $(3.2 \mathrm{eV})$ in nature, which must be excited by UV-

College of Chemistry \& Chemical Engineering, Shaoxing University, Shaoxing, Zhejiang 312000, China. E-mail: fjliu@usx.edu.cn

$\dagger$ Electronic supplementary information (ESI) available. See DOI: 10.1039/c7ra01368j light. However, UV-light accounts for rather limited content of solar radiation energy. ${ }^{22-24}$ Therefore, extended photocatalytic response of traditional $\mathrm{TiO}_{2}$ materials into visible light region and properly reduce charge-carrier recombination rate would greatly promote their practical applications. ${ }^{22-28}$ Up to now, several methods have been used to decrease the band gap energy of $\mathrm{TiO}_{2}$, including defects generation by $\mathrm{H}_{2}$ reduction, ${ }^{29-31}$ doping by transition metal ${ }^{32,33}$ and nonmetallic ions ( $\mathrm{S}, \mathrm{N}, \mathrm{C}$ etc.) into $\mathrm{TiO}_{2}$ lattice. ${ }^{33-35}$ However, the reported modification processes were usually performed under rather complicated or harsh conditions. ${ }^{27,32-37}$ Meanwhile, the reported visible light active $\mathrm{TiO}_{2}$ based photocatalysts usually show poor porosity or nanocrystalline morphology, which lead to the drawbacks such as low exposure degree of catalytically active sites, easily sintering and complicated separation processes from the reaction mixtures. ${ }^{2,8,21,31-36}$

The preparation of mesoporous $\mathrm{TiO}_{2}$ monolith with micrometer sizes could overcome the above problems. However, the mesostructures collapse and lose most of the porosity after being heated up to $300-350{ }^{\circ} \mathrm{C}$ because of the intrinsical crystallization of anatase phase. ${ }^{2,21,38-40}$ An alternative way is to immobilize $\mathrm{TiO}_{2}$ nanocrystals into ordered mesoporous materials, which usually show enhanced stability of mesostructures at high temperatures. ${ }^{2,21,37}$ Notably, ordered mesoporous materials show unique 
structural characteristics including controllable morphology, large BET surface areas, versatile frameworks, ordered and uniform mesopores, which strongly enhance the accessibility of catalytically active sites and simplify their regeneration processes.,21,37,41-43 For instance, Zhao and coworkers successfully immobilized active $\mathrm{TiO}_{2}$ nanocrystals onto the networks of ordered mesoporous $\mathrm{TiO}_{2}$ and carbon, which showed much improved photocatalytic activities for degradation of organic dyes in comparison with commercial P25 irradiated with UV-light., ${ }^{2,21}$ However, it remains a challenge to synthesize ordered mesoporous $\mathrm{TiO}_{2}$ based photocatalysts with visible-light response.

In this work, we innovatively developed high temperature (180 ${ }^{\circ} \mathrm{C}$ ) hydrothermal technology to the synthesis of carbon doped, ordered mesoporous $\mathrm{SiO}_{2}-\mathrm{TiO}_{2}$ nanocomposites (C-OMS@TiO $x \mathrm{~s}$ ), the ordered mesostructure was formed from self assembly of block copolymer templates with $\mathrm{Si}$, Ti precursors. Interestingly, the unique high temperature $\left(180{ }^{\circ} \mathrm{C}\right)$ hydrothermal technology results in the doping of carbon atom into $\mathrm{TiO}_{2}$ lattice, which makes the synthesized C-OMS@TiO ${ }_{2}-x$ s are sensitive to visible light due to the changes of band gap of $\mathrm{TiO}_{2}$ nanocrystals in these samples. Notably, this phenomenon can not be found in other ordered mesoporous $\mathrm{TiO}_{2}$ based nanocomposited materials. ${ }^{2,21}$ The usage of hydrothermal technology induced modification of $\mathrm{TiO}_{2}$ materials with heteroatom in order to adjust their band gap have not been reported previously. Combination of the characteristics of large BET surface areas, ordered and uniform mesopores and visible light adsorption property, C-OMS@ $\mathrm{TiO}_{2}-x \mathrm{~s}$ show excellent activities and good reusability for degradation of organic pollutants such as rhodamine B (RhB), methyl orange (MO) and $p$-nitrophenol (PNP) irradiated with visible light.

\section{Results and discussion}

The structural ordering of synthesized C-OMS@TiO ${ }_{2}-x \mathrm{~s}$ was examined by small angle X-ray diffraction (XRD), as shown in Fig. 1. The as synthesized F127-C-OMS@TiO ${ }_{2}-4.0$ shows three

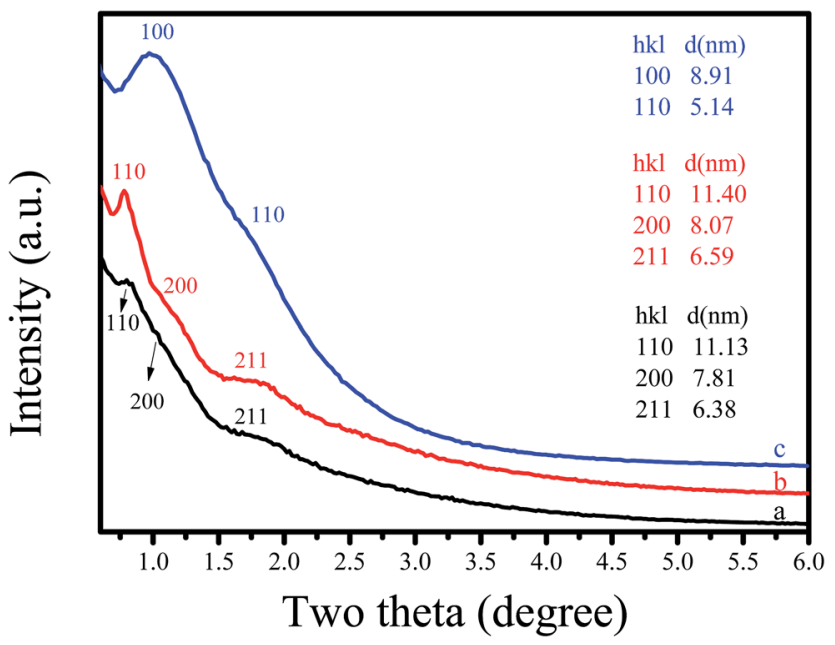

Fig. 1 Small-angle XRD pattern of (a) as synthesized F127-C$\mathrm{OMSOTiO}_{2}-4.0$, (b) $\mathrm{F} 127-\mathrm{C}-\mathrm{OMS} \mathrm{aTiO}_{2}-4.0$ and (c) P123-C$\mathrm{OMSATiO}_{2}-4.0$ peaks associated with (110), (200), and (211) reflections at the $2 \theta$ range of $0.5-2^{\circ}$, indicating the presence of highly ordered bodycentered cubic mesostructure $(\operatorname{Im} \overline{3} m)$ in the sample. After calcination, the diffraction peaks associated with (110) and (200), and (211) reflections become more resolved at the $2 \theta$ range of $0.5-2^{\circ}$. The as synthesized F127-C-OMS@ $\mathrm{TiO}_{2}-4.0$ and F127-C-OMS@ $\mathrm{TiO}_{2}-4.0$ show similar $d$-spacing values $\left(d_{110}=\right.$ $11.13 \& 11.40 \mathrm{~nm})$, corresponding to the unit cell parameters of 15.74 \& 16.12 nm. Similarly, P123-C-OMS@TiO $2-4.0$ shows two peaks associated with (100) and (110) reflections at the $2 \theta$ range of $0.5-2^{\circ}$, indicating the presence of highly ordered mesopores with $2 \mathrm{D}$ hexagonal mesostructures $(p 6 \mathrm{~mm})$, which gives the $d_{100^{-}}$ spacing values at $8.91 \mathrm{~nm}$. The different mesostructures and $d_{100}$-spacing values of F127-C-OMS@ $\mathrm{TiO}_{2}-4.0$ and P123-C-

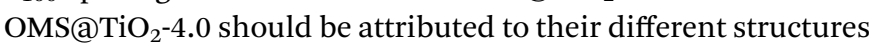
of block copolymer templates.

Fig. 2 shows wide angle XRD patterns of various C$\mathrm{OMS} @ \mathrm{TiO}_{2}-x \mathrm{~s}$ and $\mathrm{F} 127-\mathrm{TiO}_{2}$ synthesized under the same conditions. Notably, as synthesized C-OMS@TiO ${ }_{2}-x \mathrm{~s}$ exhibit several weak peaks indexed as 101, 004, 200, 105, 211 and 204 reflections, which are assigned to typical anatase phase characteristics. After calcination to remove templates, the characteristic peaks associated with anatase phase become more resolved., ${ }^{\mathbf{4 , 4 2}}$ Similar result could also be observed in F127-C$\mathrm{TiO}_{2}$, which suggests the highly crystalline degree of $\mathrm{TiO}_{2}$ active species in both C-OMS@ $\mathrm{TiO}_{2}-x \mathrm{~S}$ and $\mathrm{F} 127-\mathrm{C}-\mathrm{TiO}_{2}$. Except for anatase phase, the weak peaks at around $2 \theta=27.4,55.1$ and $70.2^{\circ}$ associated with rutile phase could also be observed in COMS@TiO ${ }_{2}-x \mathrm{~S}$ and $\mathrm{F} 127-\mathrm{C}-\mathrm{TiO}_{2},{ }^{\mathbf{4 , 9}, 42}$ which exists in the calcinated samples, suggesting polymorphism phenomenon of crystalline $\mathrm{TiO}_{2}$ in these samples.

Fig. 3 shows the $\mathrm{N}_{2}$ adsorption-desorption isotherms at $-196{ }^{\circ} \mathrm{C}$ and Barrett-Joyner-Halenda $(\mathrm{BJH})$ pore size distributions of synthesized C-OMS@TiO ${ }_{2}-x \mathrm{~s}$. The C-OMS@TiO ${ }_{2}-x \mathrm{~s}$ show typical type-IV isotherms with low $\mathrm{N}_{2}$ uptake at low relative

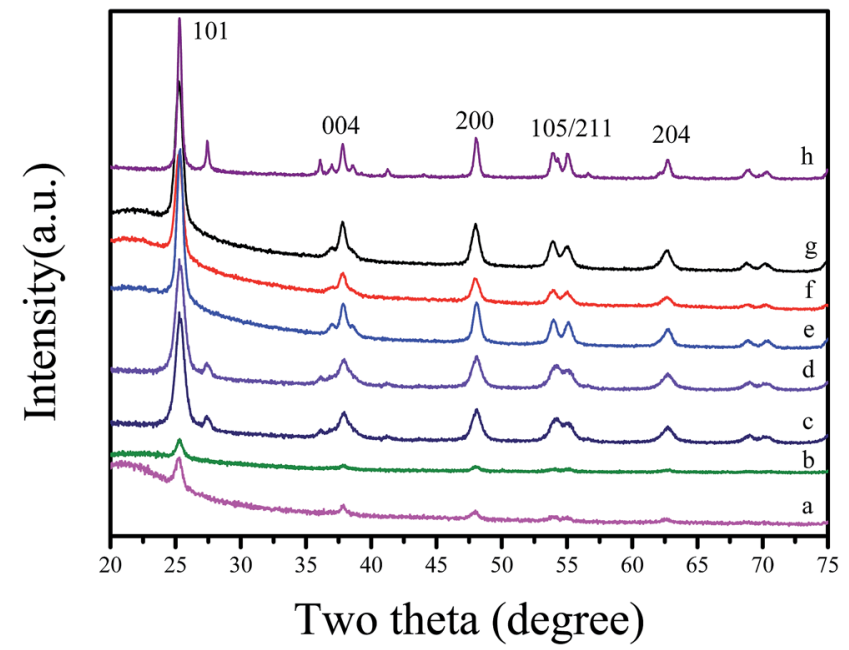

Fig. 2 Wide-angle XRD pattern of (a) as synthesized F127-C$\mathrm{OMS}_{\mathrm{CTiO}}-4.0$, (b) as synthesized P123-C-OMS@ $\mathrm{TTiO}_{2}-4.0$, (c) F127C-OMSaTiO -2.0 , (d) F127-C-OMSOTiO -4.0 , (e) F127-C-

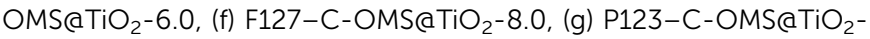
4.0 and (h) $\mathrm{F} 127-\mathrm{C}-\mathrm{TiO}_{2}$. 


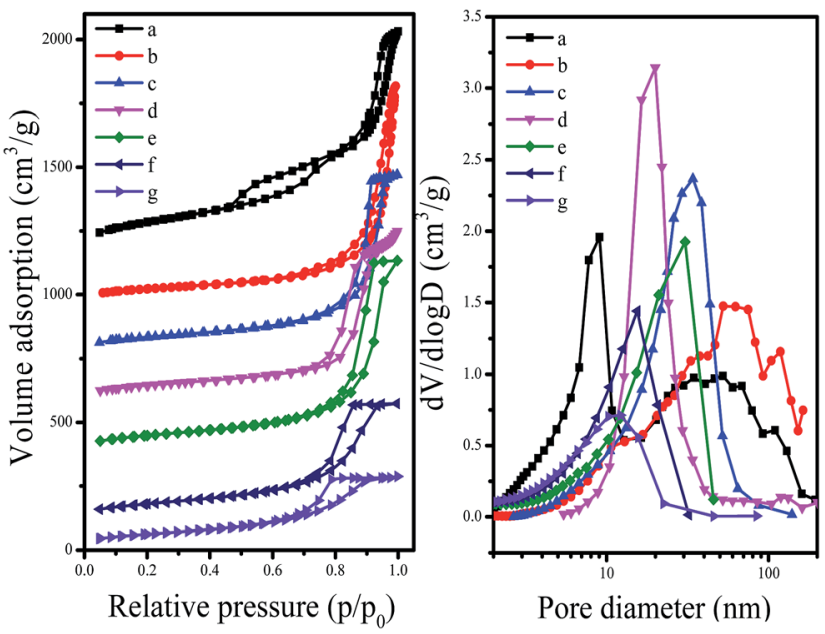

Fig. $3 \mathrm{~N}_{2}$ isotherms at $-196{ }^{\circ} \mathrm{C}$ and $\mathrm{BJH}$ pore size distributions of (a) F127-C-OMS@TiO2-9.0, (b) F127-C-OMS@TiO $2-2.0$, (c) F127-C$\mathrm{OMSOTiO}_{2}-4.0$, (d) P123-C-OMSaTiO $2-2.0$, (e) F127-C-OMSaTiO ${ }_{2}^{-}$ 6.0, (f) F127-C-OMS $\mathrm{CTiO}_{2}-8.0$ and (g) P123-C-OMS $\mathrm{CTiO}_{2}-4.0$. The isotherms of (a)-(f) are offset 1000,900,700,500, 300 and $100 \mathrm{~cm}^{3}$ $\mathrm{g}^{-1}$, respectively.

pressure, and high $\mathrm{N}_{2}$ uptake at high relative pressure, suggesting presence abundant mesopores in these samples. The $\mathrm{N}_{2}$ isotherms of C-OMS@ $\mathrm{TiO}_{2}-x \mathrm{~s}$ display steep increase at the relative pressure of $0.75-0.99$, indicating relatively narrow pore size distributions centered at 11.1-54.2 $\mathrm{nm}$. The calculated textural properties of synthesized C-OMS@TiO ${ }_{2}-x$ s are summarized in Table 1. The BET surface areas and total pore volumes of COMS@TiO 2 - $x$ s are in the range of $224-553 \mathrm{~m}^{2} \mathrm{~g}^{-1}$ and $0.45-1.40$ $\mathrm{cm}^{3} \mathrm{~g}^{-1}$, respectively. It is found that the pore sizes of $\mathrm{C}$ OMS@TiO 2 - $x$ S increase as the $\mathrm{TiO}_{2}$ amount increases (Fig. 3b), which exhibits linear relationship (Fig. S1 $\dagger$ ). This phenomenon can be explained by an enlargement of $\mathrm{TiO}_{2}$ nanocrystals onto the network of $\mathrm{C}-\mathrm{OMS} @ \mathrm{TiO}_{2}-x \mathrm{~s}$, which results in the larger aggregated mesopores in these samples.

Fig. 4 shows TEM and HR-TEM images of P123-C-OMS@TiO ${ }_{2}^{-}$ 4.0 and F127-C-OMS@TiO ${ }_{2}$-4.0. P123-C-OMS@TiO ${ }_{2}-4.0$ shows highly ordered mesopores with hexagonal symmetry (Fig. 4a and b), and $\mathrm{TiO}_{2}$ nanocrystals species with uniform sizes were homogeneously dispersed onto the network of P123-C-

Table 1 The structural parameters of various $\mathrm{C}-\mathrm{OMS} \mathrm{aTiO}_{2}-x \mathrm{~S}$

\begin{tabular}{|c|c|c|c|c|}
\hline Run & Samples & $\begin{array}{l}S_{\mathrm{BET}}{ }^{a} \\
\left(\mathrm{~m}^{2} \mathrm{~g}^{-1}\right)\end{array}$ & $\begin{array}{l}V_{\mathrm{t}}^{a} \\
\left(\mathrm{~cm}^{3} \mathrm{~g}^{-1}\right)\end{array}$ & $\begin{array}{l}D_{\mathrm{p}}^{b} \\
(\mathrm{~nm})\end{array}$ \\
\hline 1 & F127-C-OMS@TiO $2-2.0$ & 230 & 1.28 & 54.2 \\
\hline 2 & F127-C-OMS@ $\mathrm{TiO}_{2}-4.0$ & 260 & 1.12 & 34.5 \\
\hline 3 & F127-C-OMS@ $\mathrm{TiO}_{2}-6.0$ & 303 & 1.19 & 29.1 \\
\hline 4 & F127-C-OMS@ $\mathrm{TiO}_{2}-8.0$ & 288 & 0.73 & 15.2 \\
\hline 5 & F127-C-OMS@ $\mathrm{TiO}_{2}-9.0$ & 553 & 1.40 & 8.6 \\
\hline 6 & P123-C-OMS@ $\mathrm{TiO}_{2}-2.0$ & 279 & 1.06 & 18.9 \\
\hline 7 & P123-C-OMS@ $\mathrm{TiO}_{2}-4.0$ & 224 & 0.45 & 11.1 \\
\hline
\end{tabular}

${ }^{a}$ BET surface areas and pore volumes were estimated from $\mathrm{N}_{2}$ adsorption isotherms. ${ }^{b}$ Pore size distribution was estimated from BJH model.

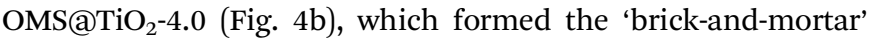
nanostructures. This is in agreement with small angle XRD results. Similarly, highly ordered mesopores with body centered structure $(\operatorname{Im} \overline{3} m)$ could also be found in F127-C-OMS@TiO ${ }_{2}-4.0$ (Fig. 4d). The high resolution TEM images show that the $\mathrm{TiO}_{2}$ species confined into nanopores of F127-C-OMS@ $\mathrm{TiO}_{2}-4.0$ and P123-C-OMS@ $\mathrm{TiO}_{2}-4.0$, exhibit several crystal lattice (Fig. 4c, e and $\mathrm{f}$ ), which is in consistent with the wide angle XRD results. Furthermore, abundant mesopores of F127-C-OMS@TiO ${ }_{2}-4.0$ could also be confirmed by STEM image (Fig. 5a), which exhibits the signals of Ti, Si, C and O (Fig. 5b). In addition, the elemental maps indicate the signals of $\mathrm{Ti}, \mathrm{Si}, \mathrm{C}$ and $\mathrm{O}$ formed a "brick-andmortar" nanostructure, which were homogeneously dispersed into F127-C-OMS@TiO $2-4.0$ (Fig. 5c-f).

Fig. 6 shows XPS spectra of F127-C-OMS@TiO ${ }_{2}-4.0$ and as synthesized F127-C-OMS@TiO ${ }_{2}-4.0$, which exhibit the signals of C 1s, O 1s, Ti $2 \mathrm{p}$ and Si $2 \mathrm{p}$. The peaks associated with Ti $2 \mathrm{p}$ are centered at around 458.5 and $464.3 \mathrm{eV}$, which are assigned to $\mathrm{Ti}^{4+}$ in $\mathrm{TiO}_{2}$ lattices. The peak associated with $\mathrm{Si} 2 \mathrm{p}$ is centered at around $103.8 \mathrm{eV}$, which is assigned to $\mathrm{Si}^{4+}$ in $\mathrm{SiO}_{2}$ species. The peaks associated with $\mathrm{O} 1 \mathrm{~s}$ are centered at around 530.0 and $533.3 \mathrm{eV}$, which are assigned to the signals of $\mathrm{Ti}-\mathrm{O}$ and $\mathrm{Si}-\mathrm{O}$, respectively. ${ }^{\mathbf{4 4}}$ The peaks associated with $\mathrm{C}$ 1s can be fitted and deconvoluted into two peaks centered at around 284.8 and $286.7 \mathrm{eV}$, which are attributed to the signals of $\mathrm{C}-\mathrm{C}$ and $\mathrm{C}-\mathrm{O}$ bonds respectively. The formation of $\mathrm{C}-\mathrm{O}$ bond should be attributed to the doping of $\mathrm{C}$ atom in the lattice of $\mathrm{TiO}_{2}$ under unique high temperature hydrothermal condition, which changes the band gap of $\mathrm{TiO}_{2}$ species in $\mathrm{C}-\mathrm{OMS} @ \mathrm{TiO}_{2}-x \mathrm{~s}$. In addition, the $\mathrm{C}$ content of F127-C-OMS@TiO -4.0 was also analyzed by elemental analysis, which shows $\mathrm{C}$ content of $0.8 \mathrm{wt} \%$, further confirming the doping of $\mathrm{C}$ atom in $\mathrm{OMS} \mathrm{TiO}_{2}-x \mathrm{~s}$. The above results confirm the successful preparation of carbon doped C-OMS@ $\mathrm{TiO}_{2}-x \mathrm{~s}$ nanocomposited photocatalysts, in good agreement with EDX and elemental maps results.

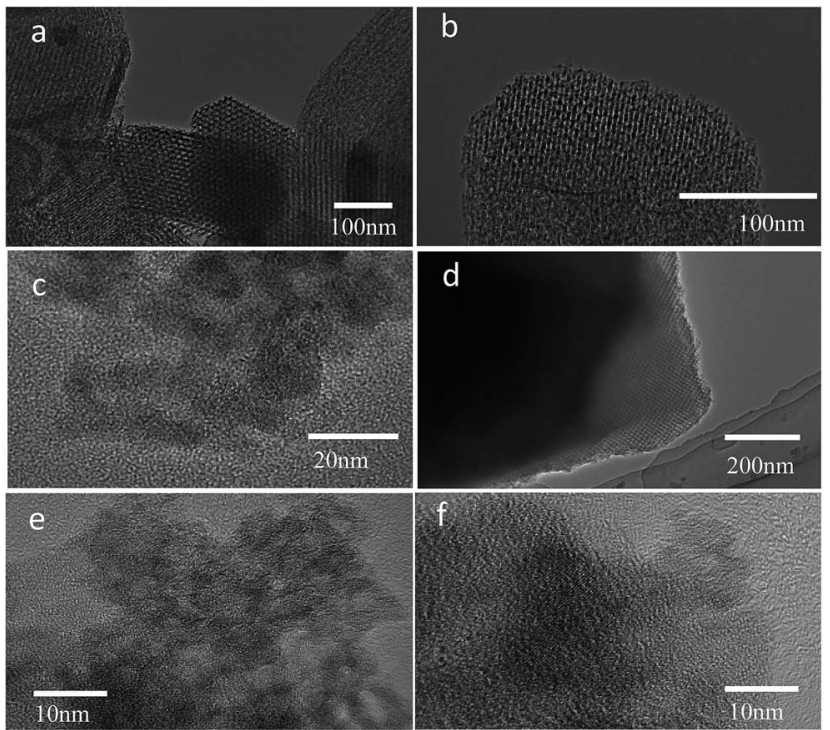

Fig. 4 TEM images of calcinated P123-C-OMS $\mathrm{aTiO}_{2}-4.0(\mathrm{a}-\mathrm{c})$ and F127-C-OMS@ $\mathrm{TiO}_{2}-4.0$ (d-f). 

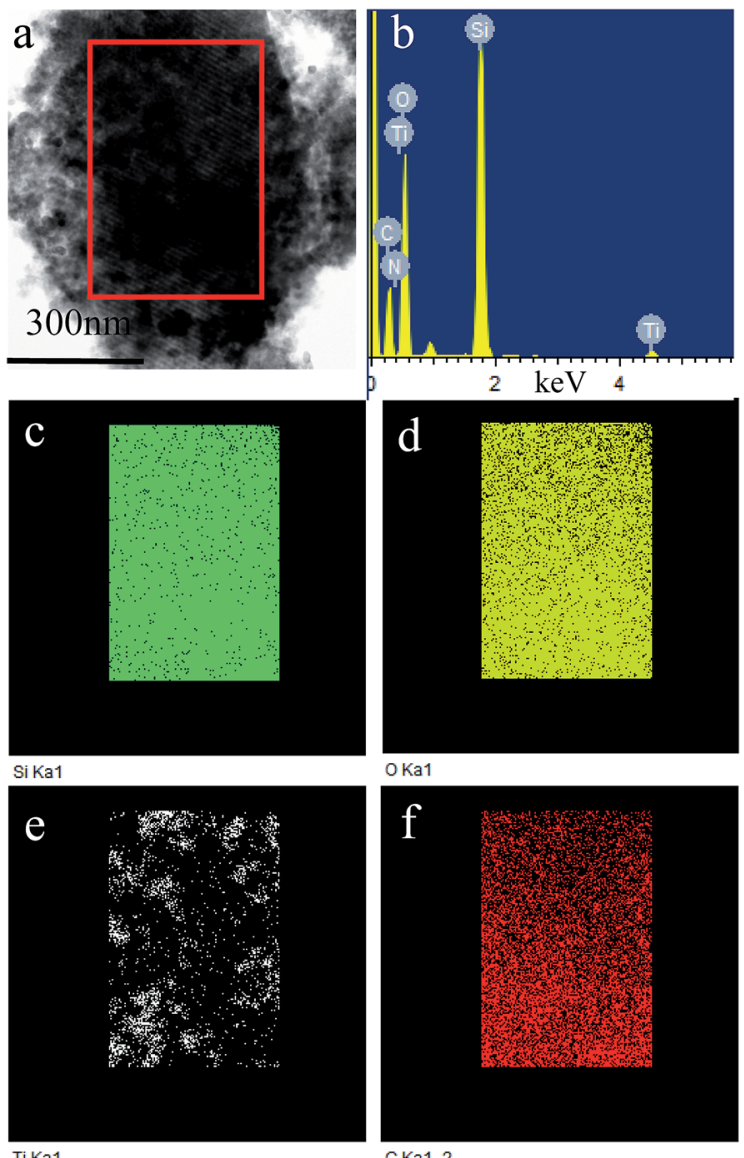

TiKa1

CKa1_2

Fig. 5 (a) STEM image, (b) EDX spectrum and (c-f) elemental maps of F127-C-OMS@ $\mathrm{TiO}_{2}-4.0$.
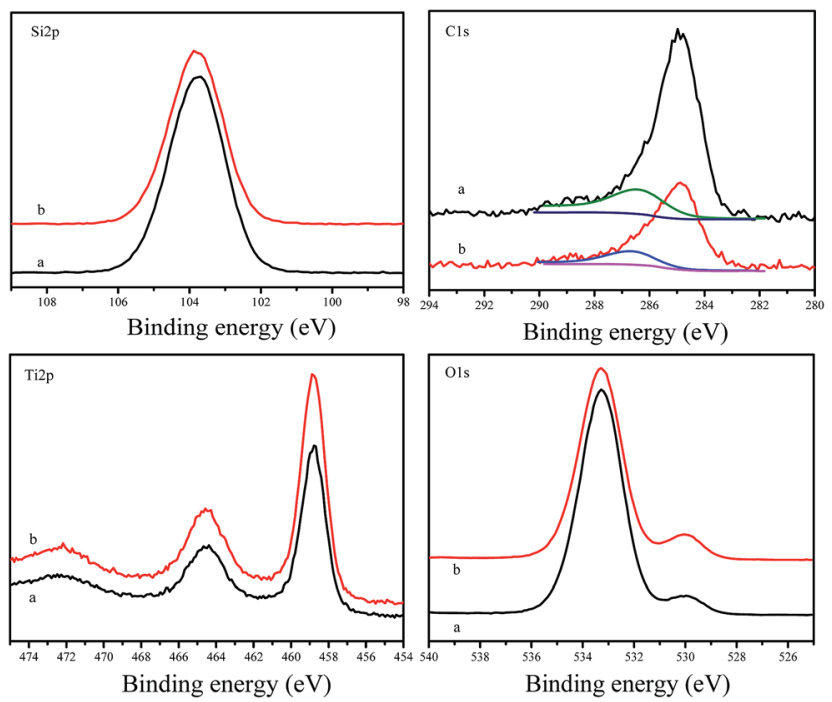

Fig. 6 XPS spectra of (a) as synthesized F127-C-OMS $\mathrm{aTiO}_{2}-4.0$ and (b) calcinated F127-C-OMS $\mathrm{CTiO}_{2}-4.0$.

Fig. 7 shows UV-vis diffuse reflectance spectra of as synthesized F127-C-OMS@TiO ${ }_{2}$-4.0-as, F127-C-OMS@TiO ${ }_{2}-4.0$, P123C-OMS@ $\mathrm{TiO}_{2}-4.0, \mathrm{~F} 127-\mathrm{C}-\mathrm{TiO}_{2}, \mathrm{~F} 127-\mathrm{OMS}$ and commercial
P25. Notably, F127-OMS and commercial P25 show the adsorption edges start from $400 \mathrm{~nm}$ and nearly no adsorption intensity in the visible-light region. In contrast, as synthesized F127-C-OMS@ $\mathrm{TiO}_{2}$-4.0, F127-C-OMS@TiO ${ }_{2}$-4.0, P123-COMS@TiO $2-4.0$ and $\mathrm{F} 127-\mathrm{C}-\mathrm{TiO}_{2}$ show relatively weak adsorption steps in visible-light region and strong adsorption peaks in UV-light region, which start from $650 \mathrm{~nm}$. The visible light response property should be attributed to their unique high temperature hydrothermal synthesis technology, which results in the doping of carbon heteroatom in the $\mathrm{TiO}_{2}$ lattices. The adjusting of band gap of $\mathrm{TiO}_{2}$ nanocrystals in porous polymers via facile high temperature solvothermal technology has been reported by us previously. ${ }^{37}$ Visible-light adsorption property of C-OMS@TiO ${ }_{2}-x \mathrm{~S}$ and $\mathrm{F} 127-\mathrm{C}-\mathrm{TiO}_{2}$ plays the key factor for their photocatalytic applications irradiated with visible light.

Fig. 8 shows photocurrent-time $(I-t)$ curves of as synthesized P123-C-OMS@ $\mathrm{TiO}_{2}-2.0$-as, as synthesized F127-C-OMS@TiO ${ }_{2}$ 2.0-as, and calcinated F127-C-OMS@TiO ${ }_{2}-2.0$ under visible light irradiation $(\lambda>400 \mathrm{~nm})$. It is well known that photoelectron chemistry test was thought to be a powerful tool to monitor the light response, generation and transportation of $\mathrm{e}_{\mathrm{CB}}{ }^{-}$of various photocatalysts. In this work, the photoelectrochemical properties of C-OMS@ $\mathrm{TiO}_{2}-x \mathrm{~s}$ materials are studied by using the P123-C-OMS@TiO ${ }_{2}-2.0-$ as, F127-C-OMS@TiO ${ }_{2}-2.0$-as and F127-C-OMS@ $\mathrm{TiO}_{2}-2.0$ as the working electrode, where Pt wire and $\mathrm{Ag} / \mathrm{AgCl}$ (saturated $\mathrm{KCl}$ ) are used as the counter and reference electrodes, respectively. Under the irradiation with visible light, the photocurrent is produced and recorded. Notably, the photocurrent with different densities formed by employing the synthesized C-OMS@ $\mathrm{TiO}_{2}-x \mathrm{~s}$ as the working electrodes, which confirm their visible photoresponse, in agreement with the result of UV-vis diffuse reflectance spectra. Meanwhile, the generated photocurrents are reproducible and stable during five on-off intermittent irradiation cycles, which show photocurrent intensities ranged from $1.68-1.83 \mu \mathrm{A}$. The presence of photocurrent is mainly resulted from the fast separation and transportation of the photogenerated $\mathrm{e}_{\mathrm{CB}}{ }^{-}$on the surface of the working electrodes. The higher visible photocurrent intensity

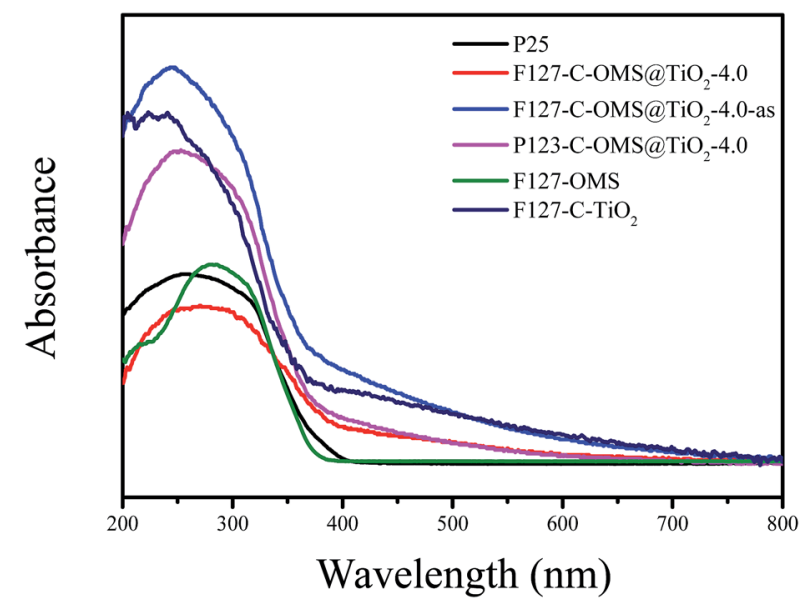

Fig. 7 UV-vis diffuse reflectance spectra of various samples. 


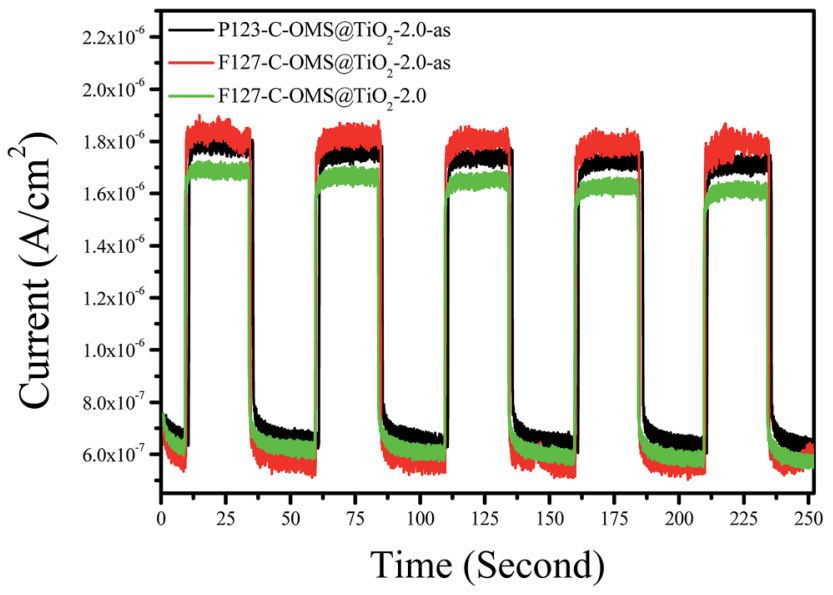

Fig. 8 Photocurrent responses of various $\mathrm{C}-\mathrm{OMS} \mathrm{aTiO}_{2}-x \mathrm{~s}$ electrodes in $0.01 \mathrm{~mol} \mathrm{~L}^{-1} \mathrm{Na}_{2} \mathrm{SO}_{4}$ electrolyte solution under visible light irradiation $(\lambda>400 \mathrm{~nm})$. The working electrode potential is constant at $+1.0 \mathrm{~V}$.

indicates the higher density of photogenerated carriers, which results in the slower $\mathrm{e}_{\mathrm{CB}}{ }^{-}-\mathrm{h}_{\mathrm{VB}}{ }^{+}$recombination rate. Compared with F127-C-OMS@TiO ${ }_{2}$-2.0, relatively higher visible photocurrent intensity of $\mathrm{F} 127-\mathrm{C}-\mathrm{OMS} @ \mathrm{TiO}_{2}$-2.0-as should be attributed to its higher content of doped carbon. ${ }^{45}$ The above characteristics were favorable for the enhancement of their visible light induced photocatalytic activities.

Fig. 9 shows TG curves of F127-C-OMS@TiO ${ }_{2}-4.0$ and P123C-OMS@TiO -4.0 before and after calcination. The as synthesized samples show two weight loss steps ranged from 50 to 150 and 230 to $500{ }^{\circ} \mathrm{C}$, which were assigned to the desorption of water and decomposition of copolymer templates in the samples. After removing the templates by calcination, the samples show only one weight loss steps ranged from 50 to $150{ }^{\circ} \mathrm{C}$ due to the desorption of water. Notably, these samples show nearly no obvious weight loss or exothermic signals in the temperatures range from $600-1000{ }^{\circ} \mathrm{C}$, which indicates their ultrastable frameworks.

Fig. 10 shows the concentrations versus reaction time for degradation of $\mathrm{RhB}$ over C-OMS@ $\mathrm{TiO}_{2}-x \mathrm{~s}, \mathrm{~F} 127-\mathrm{C}-\mathrm{TiO}_{2}$ and

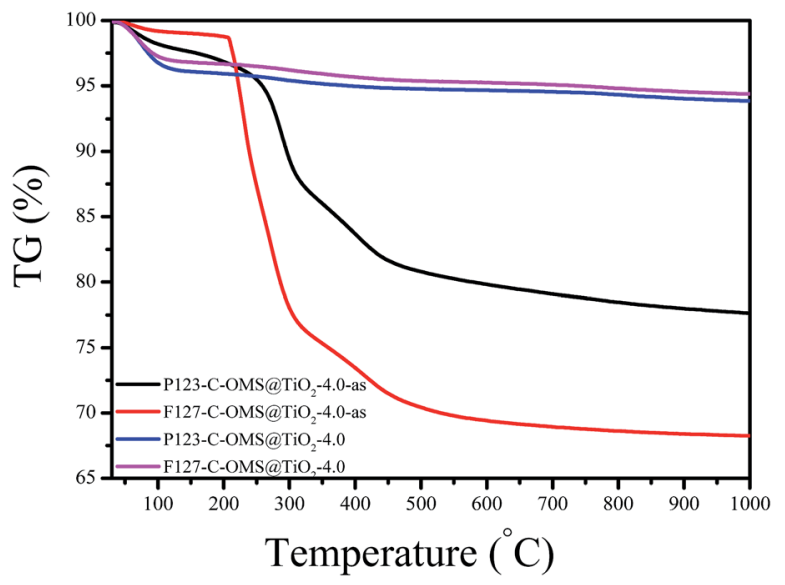

Fig. 9 TG curves of various $\mathrm{C}-\mathrm{OMS} \mathrm{CTiO}_{2}-x \mathrm{~s}$.

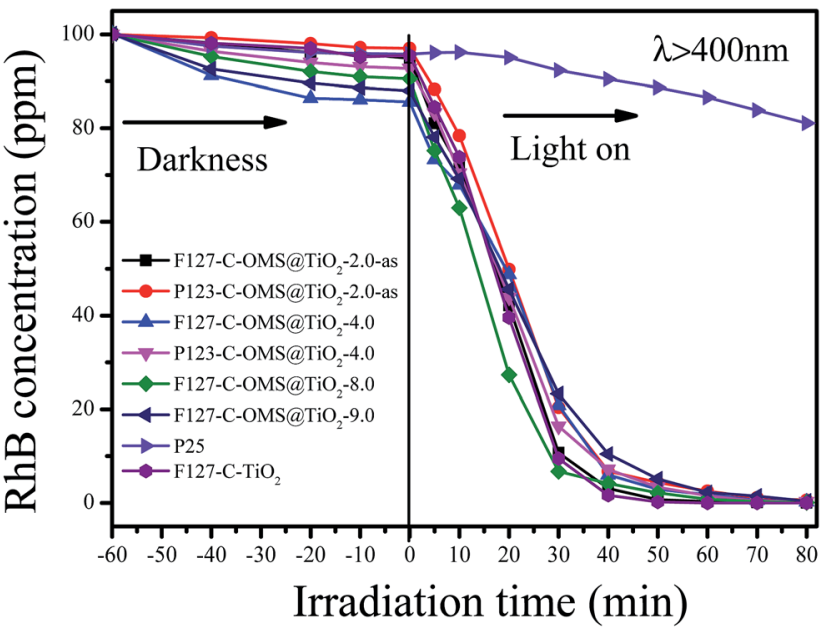

Fig. 10 Adsorption property and photocatalytic activity of various samples towards the degradation of RhB irradiated with visible light $(400<\lambda<680 \mathrm{~nm})$.

commercial P25 irradiated with visible light. Before irradiation, the reaction mixture was stirred in darkness for $30 \mathrm{~min}$ to reach adsorption equilibrium, and all the samples show limited adsorption capacities for RhB. When the reaction mixture was exposed to visible light, the concentrations of $\mathrm{RhB}$ quickly decreased catalyzed by C-OMS@ $\mathrm{TiO}_{2}-x \mathrm{~s}$ and $\mathrm{F} 127-\mathrm{C}-\mathrm{TiO}_{2}$, which is much better than that of commercial P25. For instance, the concentrations of RhB decrease from 97.4 to $74.2 \mathrm{ppm}$ only after 10 min reaction in presence of $\mathrm{F} 127-\mathrm{C}-\mathrm{TiO}_{2}$. Further prolong the reaction time up to $30 \mathrm{~min}$, the concentration of $\mathrm{RhB}$ was decreased up to $9.7 \mathrm{ppm}$, which can be fully decomposed after 40 min irradiation. Similarly, the concentrations of $\mathrm{RhB}$ change from 86.5-98.5 to $61.7-78.3 \mathrm{ppm}$ after $10 \mathrm{~min}$ reaction in presence of C-OMS@TiO ${ }_{2}-x \mathrm{~S}$ catalysts; further prolong the reaction time to $50 \mathrm{~min}$, nearly all of RhB has been catalyzed decomposition. In contrast, the concentration of $\mathrm{RhB}$ was as high as 92.1 ppm after 30 min reaction catalyzed by commercial P25. Even prolong the reaction time to $80 \mathrm{~min}$, the concentration of $\mathrm{RhB}$ was still up to $81.5 \mathrm{ppm}$ catalyzed by commercial P25. The excellent activities of $\mathrm{C}$-OMS@ $@ \mathrm{TiO}_{2}-x \mathrm{~S}$ and $\mathrm{F} 127-\mathrm{C}-\mathrm{TiO}_{2}$ in visible light region were attributed to their enhanced visible light adsorption properties. In fact, $\mathrm{SiO}_{2}$ and $\mathrm{TiO}_{2}$ act as the role of mortar and brick in C-OMS@TiO ${ }_{2}-x \mathrm{~s}$, which formed unique "brick-and-mortar" nanostructure. The "brick-and-mortar" structure was favorable for formation of ordered mesopores in C$\mathrm{OMS} \mathrm{TiO}_{2}-x \mathrm{~s}$, which strongly enhance mass transfer and exposure degree of $\mathrm{TiO}_{2}$ active sites in process of photocatalysis. Therefore, although F127-C-OMS@ $\mathrm{TiO}_{2}$-2.0-as show much lower $\mathrm{TiO}_{2}$ active site in comparison with $\mathrm{F} 127-\mathrm{C}-\mathrm{TiO}_{2}$, the degradation activity of $\mathrm{F} 127-\mathrm{C}-\mathrm{OMS} @ \mathrm{TiO}_{2}-2.0$-as is still as comparable as that of $\mathrm{F} 127-\mathrm{C}-\mathrm{TiO}_{2}$.

The degradation processes of RhB were also monitored by UV-vis adsorption spectra (Fig. S2 $\dagger$ ). The adsorption peaks associated with $\mathrm{RhB}$ decreases with increase in reaction time catalyzed by $\mathrm{F} 127-\mathrm{C}-\mathrm{OMS} @ \mathrm{TiO}_{2}-4.0$ photocatalyst. The peaks associated with $\mathrm{RhB}$ nearly disappeared when the reaction 


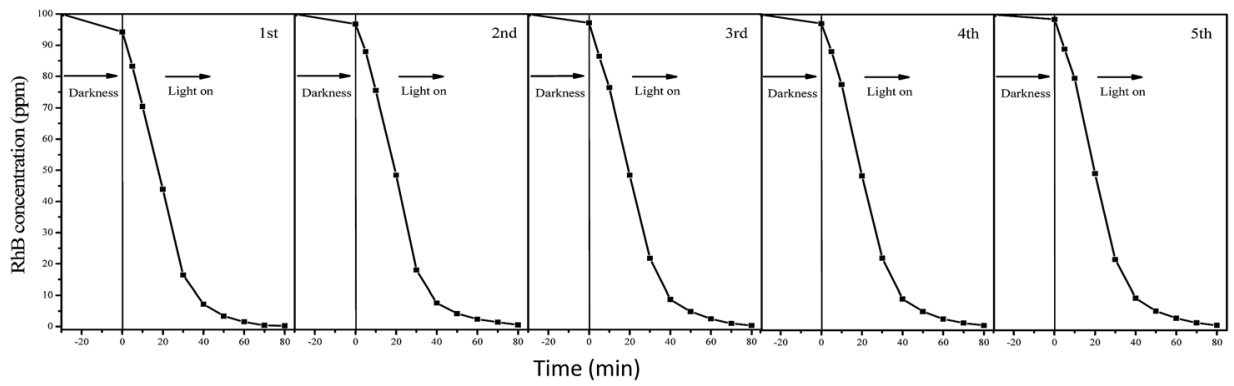

Fig. 11 Cycling of $\mathrm{P} 123-\mathrm{C}-\mathrm{OMS}\left(\mathrm{ATiO}_{2}-2.0\right.$ in degradation of $\mathrm{RhB}$ in the water irradiated with visible light $(\lambda>400 \mathrm{~nm})$.

mixture was irradiated with visible light for $80 \mathrm{~min}$, and no other additional peaks could be observed, which further confirm completely decomposition of $\mathrm{RhB}$ in the water.

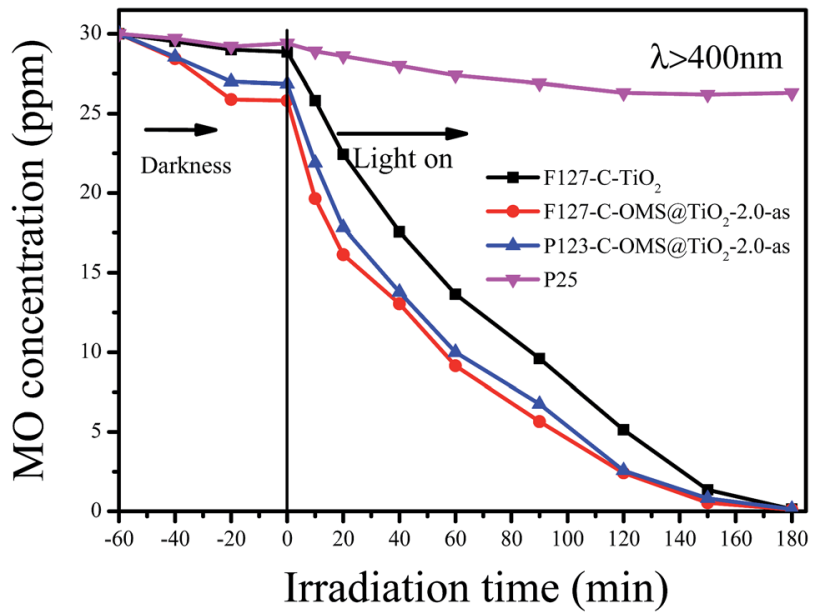

Fig. 12 Adsorption property and photocatalytic activity of various samples towards the degradation of $\mathrm{MO}$ irradiated with visible light $(400<\lambda<680 \mathrm{~nm})$.

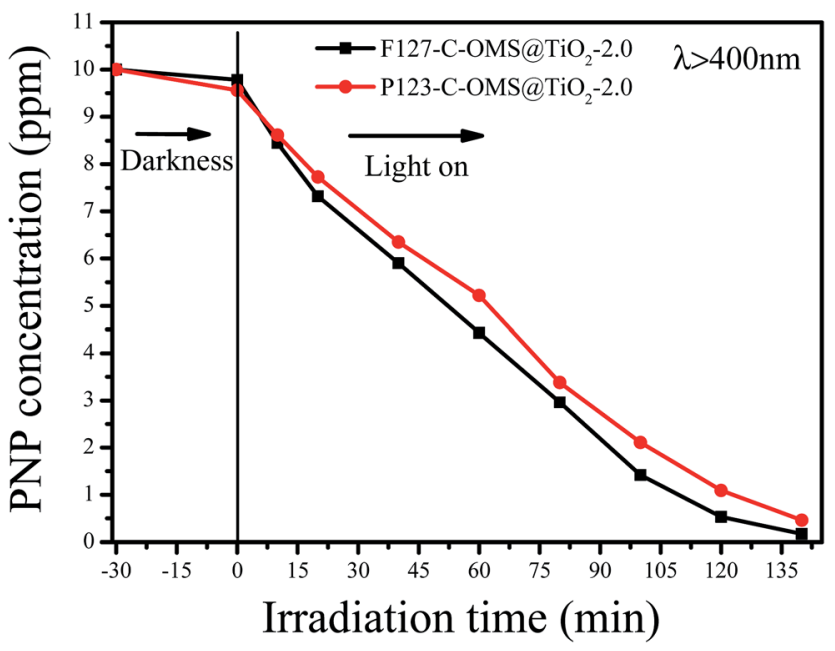

Fig. 13 Adsorption property and photocatalytic activity of various samples towards the degradation of PNP irradiated with visible light $(400<\lambda<680 \mathrm{~nm})$.
Meanwhile, the TOC values of reaction mixture catalyzed by F127-C-OMS@ $\mathrm{TiO}_{2}-4.0$ and $\mathrm{F} 127-\mathrm{C}-\mathrm{TiO}_{2}$ were also investigated (as shown in Fig. S3†), which decrease with the reaction time increase. When the irradiation time was up to $150 \mathrm{~min}$, nearly $90 \%$ of organic carbon was removed from the reaction mixture irradiated with visible light, which basically avoids the secondary pollution of the water. On the other hand, C-

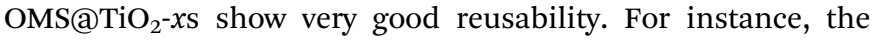
decreasing of activity of P123-C-OMS@TiO ${ }_{2}-2.0$ can not be observed after 5 cycles, suggesting the long-term stabilities of C-

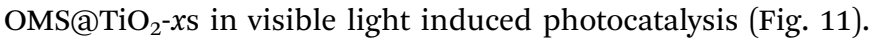
Good reusability should be attributed to their very stable framework, abundant and ordered mesopores, which strongly enhance their anti-choking and anti-sintering abilities.

Except for RhB, C-OMS@TiO 2 -xs were also very active for catalyzing degradation of MO and PNP in the water. Fig. 12 shows kinetic curves for degradation of MO over various samples irradiated with visible light. Notably, all the samples show limited adsorption contents for MO under darkness. When the reaction mixture was exposed to visible light, the concentrations of MO quickly decreased catalyzed by as made F127-C-OMS@TiO ${ }_{2}-2.0$, as made P123-C-OMS@TiO ${ }_{2}-2.0$ and F127- $\mathrm{TiO}_{2}$, nearly all of $\mathrm{MO}$ was decomposed (from 29.3 to 0.3 $\mathrm{ppm}$ ) within $180 \mathrm{~min}$ of irradiation. In contrast, the concentration of MO was still up to $26.3 \mathrm{ppm}$ after $180 \mathrm{~min}$ of reaction in presence of commercial P25. Similar results could also be observed for degradation of PNP, after 140 min irradiation with visible light, nearly all of PNP in the water has been catalyzed decomposition in presence of $\mathrm{F} 127-\mathrm{C}-\mathrm{OMS} @ \mathrm{TiO}_{2}-2.0$ and P123-C-OMS@TiO 2 -2.0 photocatalysts (Fig. 13). The above results confirmed that $\mathrm{C}-\mathrm{OMS} @ \mathrm{TiO}_{2}-x \mathrm{~s}$ and $\mathrm{F} 127-\mathrm{C}-\mathrm{TiO}_{2}$ could be used as visible light active, highly efficient and reusable photocatalysts for degradation of organic pollutants in the water.

\section{Experimental}

Chemicals and reagents

All reagents were of analytical grade and used as purchased without further purification. Tetraethyl orthosilicate (TEOS), nonionic block copolymer template poly(ethyleneoxide)-poly(propyleneoxide)-poly(ethyleneoxide), (Pluronic F127, $M_{\mathrm{w}}=$ $\left.12600, \mathrm{P} 123, M_{\mathrm{w}}=5800\right)$, tetrabutyl titanate (TBT), $\mathrm{HCl}(36.5$ wt\%), methyl orange (MO), $p$-nitrophenol (PNP) and 
rhodamine-B (RhB) were purchased from Sinopharm Chemical Reagent Co., Ltd. P25 was purchased from Degussa Co. without any treatment.

\section{Synthesis of C-OMS@TiO ${ }_{2}-x \mathrm{~s}$}

C-OMS@TiO $-x \mathrm{~s}$ were hydrothermally synthesized at the temperatures ranged from 180 to $200{ }^{\circ} \mathrm{C}$ from a self-assembly of inorganic precursors and block copolymer surfactants, where $x$ stands for the volume ratio of TEOS to TBT. As a typical run for the synthesis of F127-C-OMS@TiO 2 -2.0 or P123 - $2.4 \mathrm{~g}$ of F127 or P123 was dissolved in $76 \mathrm{~mL}$ of water with $3.3 \mathrm{~mL}$ of $\mathrm{HCl}$ (36.5 $\mathrm{wt} \%$ ), followed by addition of $6.0 \mathrm{~mL}$ of TEOS. After stirring at $40{ }^{\circ} \mathrm{C}$ for $2-3 \mathrm{~h}, 3 \mathrm{~mL}$ of TBT was then introduced into the mixture. After stirring of the mixture for another $24 \mathrm{~h}$, the reaction mixture was transferred into an autoclave and cured at 180 to $200{ }^{\circ} \mathrm{C}$ for $24 \mathrm{~h}$. The product was collected by filtration, drying at $80{ }^{\circ} \mathrm{C}$, and calcination or extraction for removing of templates. Moreover, other ${\mathrm{OMS} @ \mathrm{TiO}_{2}-x \mathrm{~s}}_{\mathrm{s}}$ samples with different volume ratios of TEOS/TBT could also be synthesized as similar procedures.

\section{Characterizations}

X-ray diffraction (XRD) patterns were obtained with a Rigaku D/ Max-2550 using nickel-filtered $\mathrm{CuK} \alpha$ radiation. Nitrogen isotherms at the temperature of liquid nitrogen were measured using Micromeritics ASAP 3020 and Tristar system, respectively. The samples were outgassed for $10 \mathrm{~h}$ at $150{ }^{\circ} \mathrm{C}$ before the measurements. The UV-visible diffuse reflectance spectra were recorded on a Perkin Elmer Lambda 20 UV/vis spectrometer. Xray photoelectron spectroscopy (XPS) spectra were performed on a Thermo ESCALAB 250 spectrometer with $\mathrm{Al} \mathrm{K} \alpha$ radiation, and binding energies were calibrated using the $\mathrm{C} 1 \mathrm{~s}$ peak at $284.9 \mathrm{eV}$. Thermogravimetric analysis (TG) was performed with a PerkinElmer TGA7 analyzer and a Perkin Elmer DTA-1700 furnace tube in flowing air. Transmission electron microscopy (TEM) experiments were performed on a JEM-2100F electron microscope (JEOL, Japan) with an acceleration voltage of 200 $\mathrm{kV}$. The total organic carbon (TOC) of the initial and irradiated samples was recorded on a Shimadzu-5000A analyzer. The concentrations of organic dyes were measured by using a NanoDrop 2000 UV-spectrophotometer based on the standard curves method.

\section{Visible light induced photocatalysis}

Visible light induced $(\lambda>400 \mathrm{~nm})$ photocatalytic degradation of RhB was carried out in a cylindrical glass under irradiation by a PLS-SXE300 $300 \mathrm{~W}$ xenon lamp equipped with a $400 \mathrm{~nm}$ cutoff filter. Typically, $10.0 \mathrm{mg}$ of catalyst was added into a cylindrical glass containing $10 \mathrm{~mL}$ of $\mathrm{RhB}$ aqueous solution with the concentration of $100 \mathrm{ppm}\left(100 \mathrm{mg} \mathrm{L}^{-1}\right)$, which was equipped with a circulation water system to maintain a constant temperature. Before irradiation, the mixture was stirred under darkness for $30 \mathrm{~min}$ to achieve sorption equilibrium. At a given time interval of irradiation, small aliquots $(0.5 \mathrm{~mL})$ were withdrawn and analyzed by UV spectroscopy at the wavelength of $555 \mathrm{~nm}$. The catalysts could be regenerated by the following procedures: (i) separation of catalysts from reaction mixtures by filtration; (ii) washing the samples with abundant ethanol to remove residual reactants or products; (iii) separation; (iv) drying of the catalyst at $60{ }^{\circ} \mathrm{C}$ under vacuum condition. Then, the catalyst was used directly for the next time.

Visible light induced $(\lambda>400 \mathrm{~nm})$ photocatalytic degradation of MO and PNP was also carried out in a cylindrical glass under irradiation by a PLS-SXE300 $300 \mathrm{~W}$ xenon lamp equipped with a $400 \mathrm{~nm}$ cutoff filter. Typically, $5 \mathrm{mg}$ of catalyst was added into a cylindrical glass containing $10 \mathrm{~mL}$ of $\mathrm{MO}(30 \mathrm{ppm})$ or $10 \mathrm{~mL}$ of PNP (10 ppm), which was equipped with a circulation water system to maintain a constant temperature. Before irradiation, the mixture was stirred under darkness for $30 \mathrm{~min}$ to achieve the adsorption equilibrium. At a given time interval of irradiation, small aliquots $(0.5 \mathrm{~mL})$ were withdrawn and analyzed by UV spectroscopy with the wavelength of 463 (MO) and $317 \mathrm{~nm}$ (PNP), respectively.

\section{Conclusions}

In summary, we exploited a high temperature hydrothermal technology in this work, which has been successfully used for preparation of ordered mesoporous $\mathrm{SiO}_{2} @ \mathrm{TiO}_{2}$ nanocomposites with controllable pore sizes and $\mathrm{Ti}$ contents. The facile high temperature hydrothermal technology results in the doping of carbon atom into $\mathrm{TiO}_{2}$ lattice in C-OMS@TiO ${ }_{2}-x \mathrm{~s}$, which changes the band gap of $\mathrm{TiO}_{2}$ in these samples. The above characteristics make C-OMS@TiO 2 - $x$ s sensitive to visible light, which show excellent activities for degradation of organic pollutants irradiated with visible light. This work develops a facile and cost effective approach to the synthesis of visible light active, ordered and stable mesoporous $\mathrm{TiO}_{2}$ materials, which is very important for the wide applications of $\mathrm{TiO}_{2}$ and its derived materials in the area of visible light photocatalysis.

\section{Acknowledgements}

This work is financially supported by the National Natural Science Foundation of China $(21573150,21203122)$ and the Natural Science Foundation of Zhejiang Province (LY15B030002). We sincerely thank Prof. Yihang Guo in Northeast Normal University for her kind helps and valuable discussion on this work.

\section{Notes and references}

1 A. Hagfeldt and M. Grätzel, Chem. Rev., 1995, 95, 49-68.

2 W. Y. Dong, Y. J. Sun, C. W. Lee, W. M. Hua, X. C. Lu, Y. F. Shi, S. C. Zhang, J. M. Chen and D. Y. Zhao, J. Am. Chem. Soc., 2007, 129, 13894-13904.

3 X. B. Chen and S. S. Mao, Chem. Rev., 2007, 107, 2891-2959.

4 A. Fujishima and K. Honda, Nature, 1972, 283, 37-38.

5 Y. J. Lee, J. B. Joo, Y. D. Yin and F. Zaera, ACS Energy Lett., 2016, 1, 52-56.

6 S. C. Sun, P. Gao, Y. Yang, P. Yang, Y. Chen and Y. Wang, ACS Appl. Mater. Interfaces, 2016, 8, 18126-18131. 
7 H. Choi, D. Shin, B. C. Yeo, T. Song, S. S. Han, N. Park and S. Kim, ACS Catal., 2016, 6, 2745-2753.

8 H. G. Yang, C. H. Sun, S. Z. Qiao, J. Zhou, G. Liu, S. C. Smith, H. M. Cheng and G. Q. Lu, Nature, 2008, 453, 638-641.

9 C. P. Sajan, S. Wageh, A. A. Al-Ghamdi, J. G. Yu and S. W. Cao, Nano Res., 2016, 9, 3-27.

10 J. M. Meichtry, R. Dillert, D. W. Bahnemann and M. I. Litter, Langmuir, 2015, 31, 6229-6236.

11 Z. G. Xiong and X. S. Zhao, J. Am. Chem. Soc., 2012, 134, 5754-5757.

12 S.-H. Lin, Y.-H. Su, H.-W. Cho, P.-Y. Kung, W.-P. Liao and J.-J. Wu, J. Mater. Chem. A, 2016, 4, 1119-1125.

13 Z. Ren, J. Wang, Z. Pan, K. Zhao, H. Zhang, Y. Li, Y. Zhao, I. Mora-Sero, J. Bisquert and X. Zhong, Chem. Mater., 2015, 27, 8398-8405.

14 K. Nakamura, T. Oshikiri, K. Ueno, Y. Wang, Y. Kamata, Y. Kotake and H. Misawa, J. Phys. Chem. Lett., 2016, 7, 1004-1009.

15 E. Guo and L. W. Yin, J. Mater. Chem. A, 2015, 3, 1339013401.

16 L. Yuan, C. Han, M. Pagliaro and Y.-J. Xu, J. Phys. Chem. C, 2016, 120, 265-273.

17 M. M. Ye, J. Jia, Z. J. Wu, C. X. Qian, R. Chen, P. G. O'Brien, W. Sun, Y. C. Dong and G. A. Ozin, Adv. Energy Mater., 2016, 7, 1601811.

18 X. H. Gao, G. R. Li, Y. Y. Xu, Z. L. Hong, C. D. Liang and Z. Lin, Angew. Chem., Int. Ed., 2015, 54, 14331-14335.

19 H. Ren, R. Yu, J. Y. Wang, Q. Jin, M. Yang, D. Mao, D. Kisailus, H. Zhao and D. Wang, Nano Lett., 2014, 14, 6679-6684.

20 T. Kawahara, Y. Konishi, H. Tada, N. Tohge, J. Nishii and S. Ito, Angew. Chem., Int. Ed., 2002, 41, 2811-2813.

21 R. L. Liu, Y. J. Ren, Y. F. Shi, F. Zhang, L. J. Zhang, B. Tu and D. Y. Zhao, Chem. Mater., 2008, 20, 1140-1146.

22 C. Wang, L. Yin, L. Zhang, N. Liu, N. Lun and Y. Qi, ACS Appl. Mater. Interfaces, 2010, 2, 3373-3377.

23 T. Pauporté and J. Rathousky, J. Phys. Chem. C, 2007, 111, 7639-7644.

24 W. Dong, Y. Zhu, H. Huang, L. Jiang, H. Zhu, C. Li, B. Chen, Z. Shi and G. Wang, J. Mater. Chem. A, 2013, 1, 10030-10036.
25 Y. Bi, H. Hu, S. Ouyang, Z. Jiao, G. Lu and J. Ye, J. Mater. Chem., 2012, 22, 14847-14850.

26 J. Luo and P. A. Maggard, Adv. Mater., 2006, 18, 514-517.

27 S. U. M. Khan, M. Al-Shahry and W. B. Ingler Jr, Science, 2002, 297, 2243-2245.

28 M. R. Elahifard, S. Rahimnejad, S. Haghighi and M. R. Gholami, J. Am. Chem. Soc., 2007, 129, 9552-9553.

29 K. Takeuchi, I. Nakamura, O. Matsumoto, S. Sugihara, M. Ando and T. Ihara, Chem. Lett., 2000, 29, 1354-1355.

30 T. Ihara, M. Miyoshi, M. Ando, S. Sugihara and Y. Iriyama, J. Mater. Sci., 2001, 36, 4201-4207.

31 X. B. Chen, L. Liu, P. Y. Yu and S. S. Mao, Science, 2011, 331, 746-750.

32 J. Choi, H. Park and M. R. Hoffmann, J. Phys. Chem. C, 2010, 114, 782-793.

33 B. Xin, Z.-H. Ren, P. Wang, J. Liu, L. Jing and H. Fu, Appl. Surf. Sci., 2007, 253, 4390-4395.

34 R. Asahi, T. Morikawa, T. Ohwaki, K. Aoki and Y. Taga, Science, 2001, 293, 269-271.

35 J.-W. Shi, C. Liu, C. He, J. Li, C. Xie, S.-H. Yang, J.-W. Chen, S. Li and C.-M. Niu, RSC Adv., 2015, 5, 17667-17675.

36 C. Xie, S. Yang, B. Li, H. Wang, J.-W. Shi, G. Li and C. Niu, J. Colloid Interface Sci., 2016, 476, 1-8.

37 F. J. Liu, W. Kong, L. Wang, I. Noshadi, Z. H. Zhang and C. Z. Qi, Nanotechnology, 2015, 26, 085705.

38 D. L. Li, H. S. Zhou and I. Honma, Nat. Mater., 2004, 3, 6572.

39 S. Y. Choi, M. Mamak, N. Coombs, N. Chopra and G. A. Ozin, Adv. Funct. Mater., 2004, 14, 335-344.

40 F. J. Liu, S. F. Zuo, X. D. Xia, J. Sun, Y. C. Zou, L. Wang, C. G. Li and C. Z. Qi, J. Mater. Chem. A, 2013, 1, 4089-4096.

41 P. D. Yang, D. Y. Zhao, D. I. Margolese, B. F. Chmelka and G. D. Stucky, Nature, 1998, 396, 152-155.

42 Y. Wan and D. Y. Zhao, Chem. Rev., 2007, 107, 2821-2860.

43 D. Y. Zhao, J. L. Feng, Q. S. Huo, N. Melosh, G. H. Fredrickson, B. F. Chmelka and G. D. Stucky, Science, 1998, 279, 548-552.

44 Y. J. Li, L. M. Yu, N. Li, W. F. Yan and X. T. Li, J. Colloid Interface Sci., 2015, 450, 246-253.

45 W. J. Ren, Z. H. Ai, F. L. Jia, L. Z. Zhang, X. X. Fan and Z. G. Zou, Appl. Catal., B, 2007, 69, 138-144. 